\title{
Absence of autoantibodies to peptides shared by HLA-B27.5 and Klebsiella pneumoniae nitrogenase in serum samples from HLA-B27 positive patients with ankylosing spondylitis and Reiter's syndrome
}

\author{
D D de Vries, A J Dekker-Saeys, E Gyodi, U Bohm, P Ivanyi
}

\begin{abstract}
Some microorganisms which are pathogenic in humans share amino acid sequences with human proteins (molecular mimicry). It has been suggested that molecular mimicry might be a reason for autoimmunity as a result of immunological cross reactivity. A homologous sequence of six amino acids has been found in both Klebsiella pneumoniae nitrogenase and the HLA-B27.5 molecule. In addition, (auto)antibodies to a synthetic peptide that contained the HLA-B27.5/klebsiella mimicking epitope have been detected in serum samples from HLA-B27 positive patients with ankylosing spondylitis and Reiter's syndrome. Confirmation of these data is important, because ankylosing spondylitis and Reiter's syndrome have so far been assumed to be 'seronegative' rheumatic diseases.

It was, however, not possible to confirm the presence of autoantibodies against the mimicking peptide in serum samples from patients with ankylosing spondylitis and Reiter's syndrome. Serum samples from 81 patients with ankylosing spondylitis, 38 patients with Reiter's syndrome, and 81 healthy blood donors were tested against the 'mimicking peptide' in an enzyme linked immunosorbent assay (ELISA). Some of the serum samples from patients showed high but non-specific binding to the mimicking peptide. A highly significant correlation between binding to plastic coated with the mimicking peptide, to plastic coated with an irrelevant peptide, and even to non-coated plastic was observed. The nature of the serum component(s) in these patient serum samples (and some control serum samples) responsible for the high non-specific binding to plastic remains unclear. It was also shown that antibodies to the HLA-B27 peptide (containing the mimicking epitope) induced in rabbits do not cross react with the klebsiella peptide and vice.versa.
\end{abstract}

The aetiology and pathogenesis of ankylosing spondylitis are still unclear. There is, however, an association between ankylosing spondylitis and HLA-B27; $90 \%$ of patients with ankylosing spondylitis are HLA-B27 positive compared with about $9 \%$ of control subjects. The results so far show that there is no difference in susceptibility to disease between the subtypes of
HLA-B27.' Thus if the B27 antigen is involved, its relevant component is a determinant shared by the subtypes and not a subtype specific sequence. The association of ankylosing spondylitis with B27 is striking, but not absolute, and variations in relative risk exist between populations. We still do not know how the HLA region determines susceptibility to ankylosing spondylitis: is it the HLA-B27 molecule itself, or an allele of a closely linked gene? Various proposals remain unproved because the experimental data cannot be confirmed or reproduced by independent laboratories.

Until now the association of HLA-B27 with reactive arthritis after infection has provided the only clue that B27 is associated with bacteria. ${ }^{2} 3$ Epidemiological studies show that ankylosing spondylitis and Reiter's syndrome are often preceded by discrete episodes of infection, mostly by enteric bacteria such as salmonella, shigella, yersinia, or klebsiella. ${ }^{4}{ }^{6}$ Infection by the latter often occurs in patients with ankylosing spondylitis. Several other observations suggest that ankylosing spondylitis is related to infection with klebsiella bacteria, but there is no definite evidence. There is much uncertainty about the results of Geczy and coworkers. Their major observations were that antibodies to klebsiella in serum samples from rabbits distinguish between lymphocytes from normal subjects and patients with ankylosing spondylitis and that filtrates from klebsiella cultures make normal B27 positive cells susceptible to lysis by rabbit antibodies to klebsiella. ${ }^{78}$ Other laboratories were not able to reproduce this experimental work, but this group showed in blind demonstrations that serum samples containing antibodies to bacteria can distinguish between ankylosing spondylitis and non-ankylosing spondylitis lymphocytes. ${ }^{9-11}$ Similar uncertainties exist for data on B27 specific cross reactions with bacterial antigens. ${ }^{5} 61213$

Closely related to these aspects is the theory of molecular mimicry. Molecular mimicry, defined as the sharing of epitopes from disparate proteins, has been found between various pathogens and human proteins. ${ }^{14}$ The finding of a hexamer amino acid sequence shared by Klebsiella pneumoniae nitrogenase and the HLAB27.5 molecule initiated a systematic search for autoimmune antibodies to HLA-B27 in serum samples from patients with ankylosing spondylitis and Reiter's syndrome. The occurrence of 
such antibodies might be the consequence of the klebsiella/B27 mimicry. The statistical probability that the observed homology in amino acid sequences has occurred by chance is low. Schwimmbeck et al examined serum samples from 24 B27 positive patients with ankylosing spondylitis and 34 B27 positive patients with Reiter's syndrome, and control subjects. ${ }^{15} \mathrm{~A}$ high degree of binding to the HLA-B27.5 peptide which contained the mimicking epitope was found in the patient groups. Although the phenomenon was only marginally significant for the serum samples from patients with ankylosing spondylitis, it was highly significant for the patients with Reiter's syndrome. The binding values of control serum samples (healthy subjects) formed the background; some patient serum samples showed an increased binding, but there was a major overlap between the binding of the patient and control serum samples. The finding of antibodies against the mimicking peptide is important because until now ankylosing spondylitis has been considered to be a seronegative rheumatic disease. These data were interpreted to indicate the presence of 'autoantibodies' against B27.

We repeated these experiments with a large group of serum samples from patients with ankylosing spondylitis and Reiter's syndrome using the same enzyme linked immunosorbent assay (ELISA) technique as Schwimmbeck et $a l .{ }^{15}$ Our data do not confirm their experimental results. Although serum samples from patients with ankylosing spondylitis and Reiter's syndrome show a higher binding to the mimicking peptide than control serum samples, this binding was non-specific. The serum samples with higher binding values also bound more strongly to an irrelevant peptide and to plastic without peptide.

\section{Patients and methods}

PATIENTS AND CONTROLS

Serum samples were obtained from 81 patients with ankylosing spondylitis and 38 patients with Reiter's syndrome. All patients were HLA-B27 positive. Serum samples from patients were collected at the van Breemen Institute for Rheumatology, Amsterdam, and at the Institute of Haematology and Blood Transfusion in Budapest. Control serum samples were obtained from 32 HLA-B27 positive and 49 non-HLA typed healthy blood donors from Amsterdam and Budapest. All serum samples were stored in aliquots at $-20^{\circ} \mathrm{C}$ until required.

\section{CLINICAL STATUS OF PATIENTS}

The patients with ankylosing spondylitis all satisfied the New York criteria for the definitive diagnosis of ankylosing spondylitis (sacroiliitis grade 3-4). In addition to sacroiliitis, all patients had abnormalities of the spinal column varying from clear overbridging syndesmophytes at various levels to a complete bamboo spine. They could all be classified as having the classical form of ankylosing spondylitis with severely affected sacroiliac joints and spinal column. None of the patients with ankylosing spondylitis had ulcerative colitis, Crohn's disease, or psoriasis. Of 81 patients with ankylosing spondylitis $79 \%$ were men with an average age of 43 (range 24-79) years.

Patients with complete and incomplete Reiter's syndrome had all developed sacroiliitis. No abnormalities of the spinal column were present. The patients predominantly showed peripheral arthritis, often combined with conjunctivitis or urethritis, or both. Of the 38 patients with Reiter's syndrome, $84 \%$ were men. The average age of the patients with Reiter's syndrome was 36 (range 25-68) years.

\section{SYNTHETIC PEPTIDES}

The peptides used in this study were similar to those described by Schwimmbeck et al ${ }^{15}$ and were synthesised by the European Veterinary Laboratory, Amsterdam, and in this institute.

Two peptides were used: (1) AKAQTDRED LRTLLRY with residues 69-84 of HLAB27.5, and (2) CNSRQTDREDELI with residues 184-196 of Klebsiella pneumoniae nitrogenase. The hexamer QTDRED is shared.

A third peptide (sequence ESLHNPYP DYRWLRTVKT) from the rabies antigen was used as an irrelevant control peptide in the ELISA.

The HLA-B27.5 peptide and the control peptide were synthesised by the solid phase method according to Merrifield, ${ }^{16}$ and modified by the European Veterinary Laboratory using the T-BOC method. The peptides were cleaved from their insoluble polystyrene resin beads with hydrogen fluoride, extracted, and lyophilised. The purity of peptides (45\%) was checked by high performance liquid chromatography (HPLC) using an LKB reversed phase $\mathrm{C}_{18}$ column.

The klebsiella peptide was synthesised using the T-bag method of Houghton, ${ }^{7}$ adapted for 9 . fluorenyl-methoxycarbamyl chemistry. The peptide was cleaved from the resin with trifluoroacetic acid, extracted, and lyophilised. The peptide was checked for purity $(50 \%)$ on a Delta Pak $\mathrm{C}_{18}$ reversed phase HPLC column.

\section{ENZYME LINKED IMMUNOSORBENT ASSAY}

The method of Schwimmbeck et al. was used. ${ }^{15}$ Wells of flexible polyvinylchloride plates (Becton Dickinson, Oxnard, CA, USA) were coated in duplicate with $0 \cdot 1 \mathrm{ml}$ of the HLAB27.5 peptide $(10 \mu \mathrm{g} / \mathrm{ml})$ in carbonate buffer (0.05 $\mathrm{M} \mathrm{Na}_{2} \mathrm{CO}_{3} / 0.05 \mathrm{M} \mathrm{NaHCO}, \mathrm{pH} \mathrm{9.6).}$ Duplicate control wells contained carbonate buffer alone or $0.1 \mathrm{ml}$ rabies irrelevant peptide $(10 \mu \mathrm{g} / \mathrm{ml})$ in carbonate buffer. After overnight incubation the wells were washed three times with a washing buffer containing phosphate buffered saline with $0.02 \%$ Tween 20 .

The remaining protein binding sites were blocked for one hour with $0.2 \mathrm{ml}$ of dilution buffer ( $10 \%$ heat inactivated fetal calf serum, $0.2 \%$ Tween in phosphate buffered saline). The serum samples $(100 \mu \mathrm{l})$ were added at dilutions of $1 / 25$ and $1 / 50$. After additional incubation for 90 minutes at room temperature the plates were washed five times. Affinity isolated peroxidase 
conjugated goat antihuman immunoglobulins $(\gamma, \alpha, \mu$, and light chains; Tago, Burlingame, CA, USA) $(100 \mu \mathrm{l})$, diluted 1000 fold in dilution buffer, were added to the plates. After incubation for 90 minutes at room temperature, the plates were washed five times in washing buffer, and $100 \mu \mathrm{l}$ of the substrate solution $(0.1 \mathrm{~mol} / \mathrm{l}$, $6 \mathrm{mg} / \mathrm{ml} 3,5,3^{\prime}, 5^{\prime}$-tetramethylbenzidine in dimethyl sulphoxide, $0.01 \%$ hydrogen peroxide in phosphate buffer, $\mathrm{pH} \mathrm{6.0)}$ was added. After 15 minutes in the dark the reaction was stopped by adding $50 \mu$ l of $2 \mathrm{M}$ sulphuric acid to each well. The absorbance was measured at $450 \mathrm{~nm}$. The coating conditions were confirmed to be effective by using a rabbit serum sample with antibodies raised against the peptides. To ensure consistency between daily assays, the same HLA-B27 control serum sample was used as a reference control in each ELISA plate and its binding value was used for correction of the day to day variations.

\section{PEPTIDE ANTISERA}

The peptides encompassing the shared amino acid hexamer QTDRED from the HLA-B27.5 hypervariable region and from Klebsiella pneumoniae nitrogenase were used to raise antibodies in serum samples from rabbits. Rabbits were immunised intramuscularly with $1 \mathrm{mg}$ of the pure peptide in phosphate buffered saline using Freund's complete adjuvant.

The reactivity and specificity of the antibodies from rabbits were determined by the ELISA assay using polystyrene high binding flat bottomed 96 well plates (Costar). The wells of these microtitre plates were coated with either HLA-B27.5 peptide or klebsiella peptide (10 $\mu \mathrm{g} / \mathrm{ml})$. The remaining binding sites were blocked with dilution buffer (containing 4\% heat inactivated horse serum(RIVM, Bilthoven), $1 \%$ Tween, and $52.5 \mathrm{~g} / \mathrm{l}$ sodium chloride, to which rabbit serum diluted $1 / 50$ to $1 / 51200$ was added. After incubation for one hour at $37^{\circ} \mathrm{C}$ the plates were washed and peroxidase conjugated horse antirabbit immunoglobulins (CLB) were added, diluted 1000 fold in dilution buffer. The absorbance was read at $450 \mathrm{~nm}$ after 30 minutes incubation in the dark.

SPECIFICITY OF THE ANTIBODIES TO PEPTIDES The specificity of the antibodies to the peptides was tested by absorption with the dissolved peptide. Serum samples containing antibodies, diluted $1 / 50$, were mixed with different concentrations of the peptides $(10 \mu \mathrm{g} /$ well, twofold diluted to $3 \mathrm{ng} / \mathrm{well}$ ), and incubated for 30 minutes at $37^{\circ} \mathrm{C}$ and 30 minutes at $4^{\circ} \mathrm{C}$ with continuous shaking. The serum samples were centrifuged for five minutes and the supernatants were added to the ELISA plates. The ELISA was performed as described earlier.

\section{STATISTICAL ANALYSIS}

The significance of the differences in serum binding in the ELISA between the groups of serum samples was evaluated by the MannWhitney $U$ test. The correlation of serum binding in the ELISA for the wells coated with different peptides and the non-coated wells was evaluated by multiple regression. The $t$ test for paired samples was used for the evaluation of the differences between serum binding under different coating conditions for each group of serum samples.

\section{Results}

\section{CROSS REACTIVITY}

Rabbit serum samples containing antibodies raised against the HLA-B27.5 peptide were tested in the ELISA. The serum bound to the HLA-B27.5 peptide coat and binding was inhibited when the serum was previously absorbed with the HLA-B27.5 peptide (fig 1). The serum did not bind to the klebsiella peptide coat, however (fig 1). Rabbit serum samples containing antibodies raised against the klebsiella peptide and tested in the ELISA bound specifically to the klebsiella peptide and showed no cross reactivity with the B27.5 peptide (fig 2). Thus the two peptide specific rabbit antibodies showed no cross reactivity, though they were raised against synthetic peptides containing the homologous hexamer QTDRED.

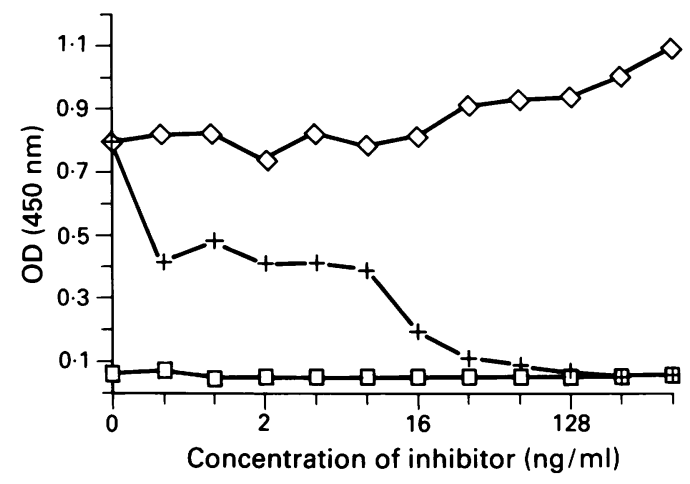

Figure 1 Blocking of antibody binding by specific peptides. The binding of the rabbit serum sample containing antibodies to the HLA-B27.5 peptide to the HLA-B27.5 peptide is inhibited by the B27.5 peptide (+) but not by the klebsiella peptide $(\diamond)$, thus showing the absence of cross reactivity between the two peptides. No binding was observed with normal rabbit serum $(\square)$.

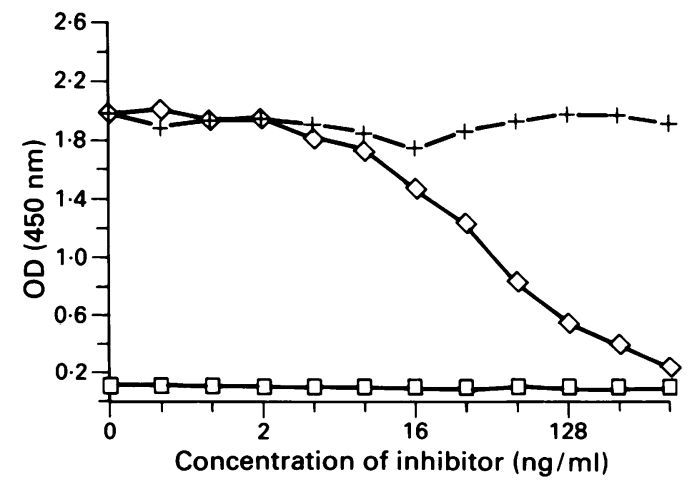

Figure 2 Blocking of antibody binding by specific peptides. The binding of the rabbit serum sample containing antibodies to the klebsiella pneumoniae nitrogenase peptide to the klebsiella peptide is inhibited by the klebsiella peptide $(\diamond)$ but not by the B27.5 peptide $(+)$, showing the absence of cross reactivity between the two peptides. No binding was observed with normal rabbit serum ( $\square$ ). 
No binding of B27.5 peptide specific antibodies was found to B27 molecules on human and HLA-B27 transgenic mouse cells ${ }^{18}$ (data not shown). This is in contrast to the observation of Schwimmbeck and Oldstone of the specific cytolytic effect of the antibodies to peptide on HLA-B27 positive cells. ${ }^{19}$

BINDING OF SERUM SAMPLES FROM PATIENTS WITH ANKYLOSING SPONDYLITIS AND REITER'S SYNDROME AND HEALTHY CONTROLS TO THE B27.5 PEPTIDE

To study the possible relevance of molecular mimicry between HLA-B27 and klebsiella for pathology, we tested serum samples from HLA-B27 positive patients with ankylosing spondylitis and Reiter's syndrome for binding to a B27.5 peptide which contained a hexamer (QTDRED) shared by HLA-B27.5 and Klebsiella pneumoniae nitrogenase molecules. The table summarises the results obtained.

The binding of serum samples from patients with ankylosing spondylitis to the B27.5

Binding of serum samples from patients and healthy control subjects to the synthetic peptide HLA-B27.5 (residues 69-84) which contains the OTDRED hexamer shared with Klebsiella pneumoniae nitrogenase. The difference between the serum samples from patients with ankylosing spondylitis and the control (non-HLA typed) group is significant $(p<0.05)$

\begin{tabular}{lllll}
\hline Subject group & $\begin{array}{l}\text { Sex ratio } \\
(F / M)\end{array}$ & $\begin{array}{l}\text { Number of } \\
\text { serum samples } \\
\text { tested }\end{array}$ & $\begin{array}{l}\text { HLA } \\
\text { phenotype }\end{array}$ & $\begin{array}{l}\text { Mean }(S D)) \\
\text { binding }\end{array}$ \\
\hline $\begin{array}{l}\text { Ankylosing spondylitis } \\
\text { Reiter's syndrome }\end{array}$ & $17 / 64$ & 81 & $27+$ & $0 \cdot 80(0 \cdot 36)$ \\
Healthy donors & $6 / 32$ & 38 & $27+$ & $0 \cdot 86(0 \cdot 50)$ \\
Healthy donors & $10 / 39$ & 49 & $\mathrm{NT}$ & $0 \cdot 69(0 \cdot 38)$ \\
\hline
\end{tabular}

$\mathbf{F}=$ female; $M$ = male; NT= not tested. peptide was significantly higher than the binding of serum samples from healthy (nonHLA typed) blood donors $(\mathrm{p}<0.05)$. The serum samples from patients with Reiter's syndrome also showed a higher binding to the B27.5 peptide than the normal serum samples but this difference was not significant (possibly due to the low number of samples and heterogeneity among the serum samples from patients with Reiter's syndrome). These data are similar to the observations of Schwimmbeck et al. ${ }^{15}$

Surprisingly, the binding of the serum samples from healthy HLA-B27 positive donors to the B27.5 peptide was relatively high. On closer inspection we found that this group of samples was stratified and contained a few unexpectedly high binding samples. Of the nine serum samples with the highest binding to the B27.5 peptide, seven were from women blood donors. Most of the serum samples with low binding to the B27.5 peptide were from men (not significant).

Taken together, binding to the $\mathrm{B} 27.5$ peptide by serum samples from patients with ankylosing spondylitis and Reiter's syndrome was higher than binding by control serum samples, though in the latter group serum samples with high binding were occasionally present.

It is important to determine whether the difference between serum samples from patients and those from healthy controls is specific for the B27.5 peptide. Two extra control experiments were performed to study this. All the serum samples in the table were also tested for binding to plastic coated with an irrelevant peptide and to non-coated plastic. High and low binding samples were observed in the two tests.
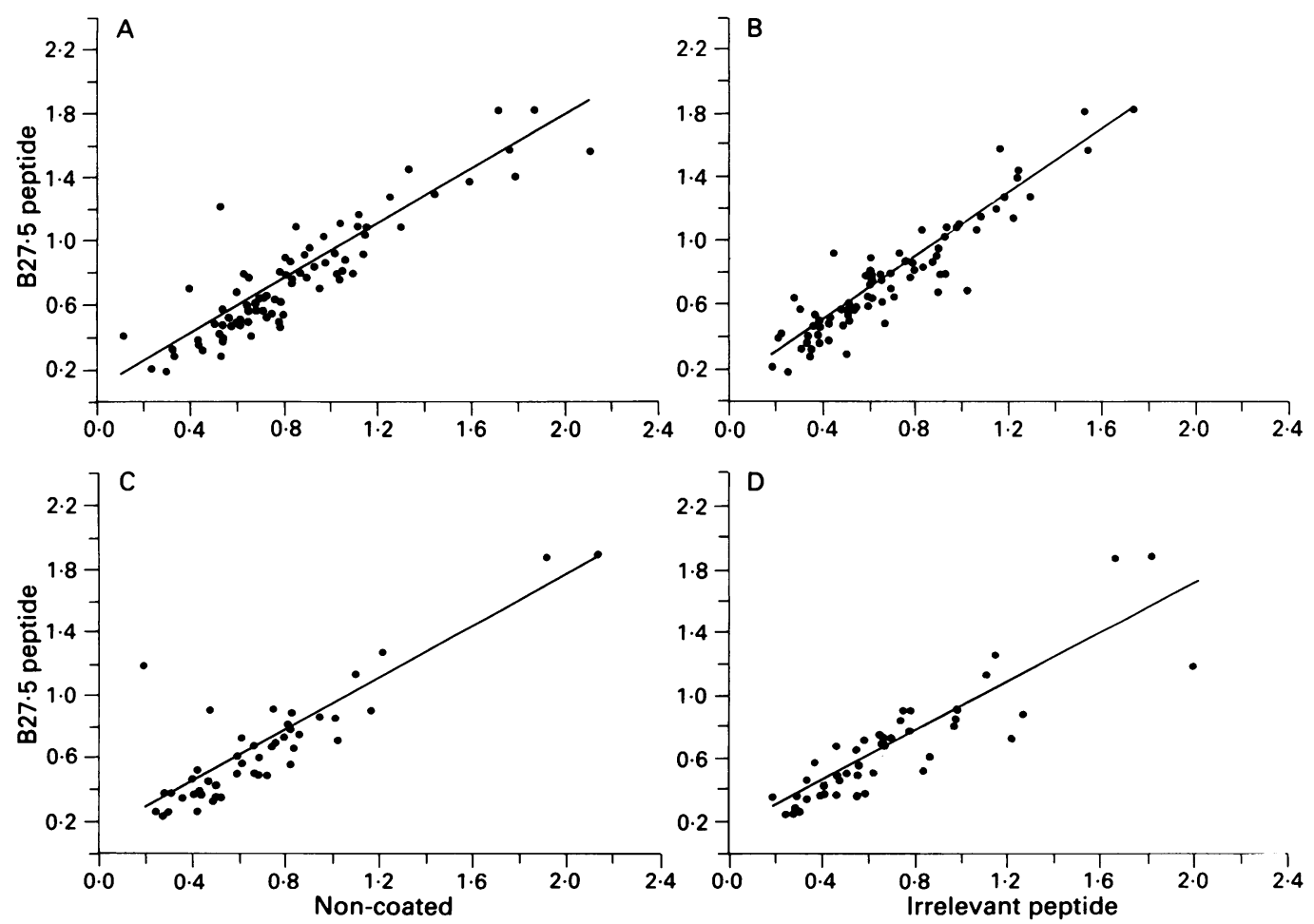

Figure 3 Binding of serum samples from patients with ankylosing spondylitis (all B27 positive) $(A, B)$ and serum samples from normal blood donors (not $H L A$ typed $)(C, D)$ to the $H L A-B 27.5$ peptide versus binding to non-coated plastic $(A, C)$ or to plastic coated with irrelevant peptide $(B, D)$. For the two groups of serum samples the binding to the B27.5 peptide versus the non-coated wells or versus the irrelevant peptide is highly correlated. The correlation coefficients $(r ; p<0.00 I)$ are as follows: (A) $0 \cdot 90 ;(B) 0 \cdot 93 ;(C) 0 \cdot 86$; and $(D) 0 \cdot 88$. 


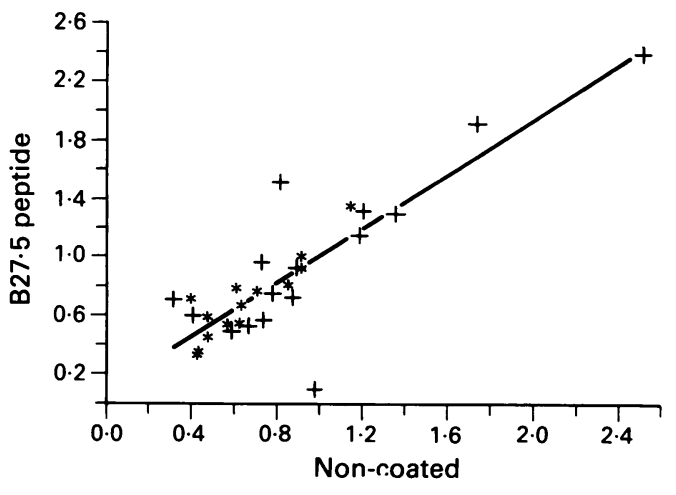

Figure 4 Binding of serum samples from healthy B27 positive blood donors to plates coated with the B27.5 peptide is correlated with binding to plastic without any coating. Serum samples from women blood donors $(+)$ show high values but this is not significantly different from the binding of serum samples from men $\left({ }^{*}\right)$. The correlation coefficient $(p=<0.001)$ is 0.86

An intriguing finding was the good correlation between the binding of individual samples in the three assays (B27.5 peptide coat, irrelevant peptide coat, and non-coated plastic). For each group of serum samples binding to the B27.5 peptide versus binding to the irrelevant peptide and binding to non-coated plates were compared. Figure 3 shows that in all comparisons the positive correlation was highly significant (correlation coefficient $r=0.83-0.93 ; p<0.001$ ), and deviations for individual samples were exceptional. Figure 3 shows the actual binding values found for individual serum samples.

Figure 4 shows the binding of the control serum samples from healthy HLA-B27 positive donors to the B27.5 peptide coat and compares this with the binding to the non-coated plastic. Serum samples from HLA-B27 positive women blood donors have a tendency to bind more to plastic but this sex difference was not statistically significant.

\section{Discussion}

The discovery of a hexamer shared by Klebsiella pneumoniae nitrogenase and the HLA-B27.5 molecule led to the suggestion that molecular mimicry might have biological consequences and provides a clue to understanding the association(s) between HLA-B27 and disease. The association of $B 27$ with reactive arthritis after infection and various other observations suggest some kind of relationship between bacteria and HLA-B27. ${ }^{3}$ 20-23

Schwimmbeck et al initiated serological experiments with synthetic peptides that contained the shared QTDRED hexamer and examined serum samples from patients with ankylosing spondylitis and Reiter's syndrome compared with control serum samples. ${ }^{15}$ Their data showed that serum samples from patients had a higher binding to the mimicking peptide than control samples. Their data also contained the following problems, however. First, not all patient serum samples (only 7/24 (29\%) ankylosing spondylitis and 18/34 (53\%) Reiter's syndrome samples) produced binding higher than the control background; second, there was pronounced high binding from serum samples from patients with Reiter's syndrome but only marginal binding from patients with ankylosing spondylitis; third, there were variations in the binding values of normal serum samples, with values occasionally slightly above the background level, which could be diluted out.

Tsuchiya et al repeated these experiments. ${ }^{24}$ They examined patients with ankylosing spondylitis and Reiter's syndrome from two different countries with discrepant results. Serum samples from Norwegian patients with ankylosing spondylitis had high binding to the mimicking peptide compared with control samples. This difference was not found for patients with Reiter's syndrome versus control subjects from Norway and for serum samples from patients with ankylosing spondylitis and Reiter's syndrome versus controls from New Mexico. Numerous control serum samples that showed high binding were samples from control women with at least one previous pregnancy. Taken together, the data of Schwimmbeck et al with serum samples from patients with Reiter's syndrome were not confirmed and only one of the two groups of serum samples from patients with ankylosing spondylitis and several normal samples showed high binding to the mimicking peptide. $^{15}$

In our experiments increased binding was observed for serum samples from patients with ankylosing spondylitis and Reiter's syndrome though this was significant only for the samples from patients with ankylosing spondylitis. These findings confirm the data of Schwimmbeck et al. ${ }^{15}$ Further analysis, however, showed that this increased binding was not specific for the B27.5 peptide. Figure 3 shows that serum samples from patients often have an increased binding to an irrelevant peptide and even to plastic without any coating. This increased binding seems to be a nonspecific phenomenon. Increased binding of serum immunoglobulins to plastic surfaces is a known phenomenon and has already been analysed. ${ }^{25} 26$ The reason for this spontaneous binding to plastic remains unclear and is difficult to explain. For instance, it was not possible to eliminate non-specific sticking by previous adsorption on pulverised tray material. ${ }^{25}$ Similar difficulties probably occurred in the work of Tsuchiya et al because they included for each serum sample controls with uncoated wells on the same microplates to correct for non-specific serum binding. ${ }^{24}$ Procedures to correct for non-specific binding were not clearly described in the work of Schwimmbeck et al. ${ }^{15}$

In the latter study few normal human serum samples exerted increased binding. We observed, like Tsuchiya's group, that high binding for a few control serum samples was comparable with that of samples from patients. Interestingly, in both studies such high binding of normal serum samples occurred more often with serum samples from women (fig 4).

In contrast with patient and normal human serum samples, high specific binding was observed with rabbit serum samples containing antibodies to the peptide (fig 1). No cross reaction between the $\mathrm{B} 27.5$ and the klebsiella 
peptide was observed, however. The same result was described by Tsuchiya et al ${ }^{24}$ and implies that the rabbit antibodies were not specifically directed against the shared QTDRED sequence of the two peptides. In similar experiments, Husby et $a l^{27}$ and Schwimmbeck and Oldstone $^{1928}$ found no cross reactivity of the antibodies to klebsiella with the B27.5 peptide, but they reported weak binding of antibodies to B27.5 peptide to the klebsiella peptide.

Ewing et al ${ }^{29}$ examined serum samples from 50 patients with ankylosing spondylitis, 22 B27 positive, and 22 B27 negative healthy controls. Binding to overlapping peptides of varying length from Klebsiella pneumoniae nitrogenase reductase and from the HLA-B27.5 molecule containing the mimicking sequence was tested by an ELISA. Although the overlap in immunoglobulin binding for patient and control serum samples was considerable, they observed a statistically significant difference. Individual serum samples showed a perfect correlation for binding with various peptides. This agrees with our findings (fig 3). The mimicking sequence (QTDRED) was not a target for cross reactivity between the B27.5 and Klebsiella pneumoniae nitrogenase reductase protein. These workers concluded that 'much wider testing of sera from the normal population and from (AS) patients' is needed to determine the specificity of immunoglobulin binding in ELISA. Thus these experiments could not elucidate whether serum samples from patients with ankylosing spondylitis contain an antibody population absent in normal control serum samples; the specificity of the binding could not be conclusively elucidated either.

In summary, our data cannot be interpreted as evidence for the presence of (auto)antibodies against the hexapeptide QTDRED shared by HLA-B27.5 and Klebsiella pneumoniae nitrogenase molecules in serum samples from patients with ankylosing spondylitis or Reiter's syndrome. We suggest that the discrepancy is because no tests were performed with an irrelevant peptide and with non-coated plastic in the studies of Schwimmbeck et al. ${ }^{15}$ The reason for the non-specific binding of such serum samples remains unclear.

HLA-B27 may have structural features that, though unique among HLA molecules, are shared with bacteria. An immune response elicited by infection with such bacteria would then cross react with itself, causing tissue damage and clinical symptoms. This 'molecular mimicry' hypothesis is based on a number of homologous amino acid sequences between HLA and other molecules and on data which describe cross reactions between HLA and bacterial antigens. There are various reports on the cross reactivity of serum samples containing antibodies to bacteria with HLA and antibodies to HLA with bacterial antigens. The report on the monoclonal antibody Ye-1 induced in mice by yersinia bacteria and reacting specifically with B27 positive cells is important. ${ }^{5}$ The avidity of Ye-1 was too low for more detailed studies, however. ${ }^{5}$

Cross reactions with bacterial antigens were also found with the monoclonal antibodies against B27 (B27M1 and B27M2). ${ }^{30-32}$ B27M1 and $B 27 M 2$ have been used to test various strains of bacteria and cross reactivity has been found with various, not well defined, components in Shigella flexneri, Shigella sonnei, Salmonella typhimurium, Klebsiella pneumoniae, and Escherichia coli.

The monoclonal antibody Ye-2, induced in mice by immunisation with HLA-B27 positive cells, reacted with a component in Yersinia psuedotuberculosis. ${ }^{12}$ It was additionally shown that antibodies raised in rabbits, immunised with a yersinia component precipitated by the Ye-2 monoclonal antibody, reacted with HLAB27 human cells.

None of these data was evaluated in more detail and analysed at the molecular level, however. Thus it is not known whether the cross reactions are due to molecular mimicry. Interestingly, cross reactivity has been observed without homology in amino acid sequences. ${ }^{13}$

The occurrence of reactive arthritis in HLAB27 positive subjects clearly shows that there is a correlation between the B27 antigen and reactivity to bacteria. The pathway along which this correlation occurs at the population level remains enigmatic and our data do not provide evidence for the mimicry theory. Although molecular mimicry is established, the biological relevance of molecular mimicry in pathology remains hypothetical.

We thank all the subjects who volunteered to participate in this study. This study was financially supported by The Dutch Rheumatism Foundation, grant no. 88/CR/072/91. The peptide ESLHNPYPDYRWLRTVKT was provided by the European Veterinary Laboratory, Amsterdam.

1 Breur Vriesendorp B S, Dekker-Saeys A J, Ivanyi P. Distribution of HLA-B27 subtypes in patients with ankylosing spondylitis: the disease is associated with a common determinant of the various B27 molecules. Ann Rheum Dis 1987; 46: 353-6.

2 Phillips $\mathrm{P}$ E. The role of infectious agents in the spondylarthropathies. Scand f Rheumatol 1988; 17: 435-43.

3 Aho $K$, Ahvonen P, Lassus A, Sievers K, Tiilikainen $K$. HLA-B27 antigen and reactive arthritis. Lancet 1973; ii: 157.

4 Welsh J, Avakian $\mathrm{H}$, Cowling P, et al. Ankylosing spondylitis, HLA-B27 and klebsiella. I. Cross-reactivity studies with HLA-B27 and klebsiella. I. Cross-reactivity stud
rabbit antisera. Br $\mathcal{E}$ Exp Pathol 1980; 61: 85-91.

5 rabbit antisera. Br f Exp Pathol 1980; 61: 85-91. Waldord R L, Yu D T Y. Ye-1, a monoclonal antibody that cross$R$ L, Yu D T Y. Ye-1, a monoclonal antibody that cross-
reacts with HLA-B27 lymphoblastoid cell lines and an arthritis causing bacteria. Clin Exp Immunol 1985; 61 503-8.

6 van Bohemen Ch G, Grumet F C, Zanen H C. Identification of HLA-B27 M1 and M2 cross-reactive antigens in klebsiella, shigella and yersinia. Immunology 1984; 52: 607-10.

7 Seager K, Bashir H V, Geczy A F, Edmonds J, de VereTyndall A. Evidence for a specific B27 associated cell surface marker on lymphocytes of patients with ankylosing spondylitis. Nature 1979; 277: 68-70.

8 Geczy A F, Alexander K, Bashir H V, Edmonds J. A factor(s) in klebsiella culture filtrates specifically modifies an HLA-B27 associated cell surface component. Nature 1980;

9 Archer J R, Stubbs M M, Curry H L F, Geczy A F. Antiserum to klebsiella K43 BTS 1 specifically lyses lymphocytes of HLA-B27 positive patients with ankylosing lymphocytes of HLA-B27 positive patients with ankylosing

10 van Rood J J, van Leeuwen A, Ivanyi P, et al. Blind conformation of Geczy factor in ankylosing spondylitis. Conformation of Geczy

11 Geczy A F, van Leeuwen A, van Rood J J, Ivanyi P, Breur B S, Cats A. Blind conformation in Leiden of Geczy facto on the cells of Dutch patients with ankylosing spondylitis. Hum Immunol 1986; 17: 239-45.

12 Chen J H, Kono D H, Yong Z, Park M S, Oldstone M B A, Yu D T Y. A yersinia pseudotuberculosis protein which cross-reacts with HLA-B27. F Immunol 1987; 139: 300311.

13 Schaack T, Yong Z, Jiajun Z, Chen J, Nakayama A, Yu D T Y. HLA-B27 mimicry might occur without homology in amino acid sequences [abstract]. Arthritis Rheum 1988;
31 (4s): c93. 
14 Oldstone M B A. Virus induced autoimmunity: molecular mimicry as a route to autoimmune disease. $\mathscr{f}$ Autoimmun $1989 ; 2$ (suppl): 187-94.

15 Schwimmbeck P L, Yu D $T$ Y, Oldstone M B A Autoantibodies to HLA B27 in the sera of HLA B27 patients with ankylosing spondylitis and Reiter's syndrome. J $\operatorname{Exp}$ Med 1987; 166: 173-81.

16 Merrifield R B. Solid phase peptide synthesis. I. The synthesis of a tetrapeptide. F Am Chem Soc 1963; 85: 2149-54.

17 Houghton R A. General methods for the rapid solid phase synthesis of large numbers of peptides: specificity of synthesis amine acids. Proc Natl Acad Sci USA 1985; 82, 5131-5.

18 Kievits F, Wijffels J, Lokhorst W, Boerenkamp W J, Ivany $P$. HLA expression and function in single and double HLA-B27 transgenic mice. Tissue Antigens 1989; 34: 50-63.

19 Schwimmbeck P L, Oldstone M B A. Molecular mimicry between human leukocyte antigen B27 and klebsiella. Consequences for spondylarthropathies. Am J Med 1988; 85: (Suppl 6A): 51-3.

20 Hakansson U, Low B, Eitrem R, Winblad S. HLA-B27 and reactive arthritis in an outbreak of salmonellosis. Tissue antigens 1975 ; 6: 366-7.

21 Archer J R, Winrow V R. HLA-B27 and the cause of arthritis: does molecular biology help? Ann Rheum Dis 1987; 46: 713-5.

22 Granfors K, Jalkanen S, Lindberg A A, et al. Salmonella lipopolysaccharide in synovial cells from patients with reactive arthritis. Lancet 1990; 335: 685-8.

23 Lahesmaa-Rantala R, Skurnik M, Granfors K, et al. A tetrapeptide shared by yersinia outer membrane protein
Yopl and HLA-B27; immune response in patients with Yopl and HLA-B27; immune response in patients with yersinia triggered reactive arthritis. In: Streilein J W, ed. Advances in gene technology. The molecular biology of immune response. Proceedings of the Miami biotechno
symposia; 1990. Oxford: IRL Press, 1990: 76.

24 Tsuchiya N, Husby G, Williams R C Jr. Studies of humoral and cell-mediated immunity to peptides shared by $\mathrm{HLA}$ -
B27.11 and Klebsiella pneumoniae nitrogenase in ankylosing spondylitis. Clin Exp Immunol 1989; 76: 354-60.

25 Conger J D, Pike B L, Nossal G J V. Analysis of the lymphocyte repertoire by polyclonal activation. Hindrance by clones yielding antibodies which bind promiscuously to plastic. F Immunol Methods 1988; 106: 181-9.

26 Haskard D O, Gul V, Archer J R. Cross-reactivity between solid-phase immunoassay plates and intermediate filaments demonstrated by human monoclonal antibodies. 7 I mmunol Methods 1985; 77: 2391 .

27 Husby G, Tsuchiya N, Schwimmbeck P L, et al. Crossreactive epitope with Klebsiella pneumoniae nitrogenase in articular tissue of HLA B27+ patients with ankylosing spondylitis. Arthritis Rheum 1989; 32: 437-45.

28 Schwimmbeck P L, Oldstone M B A. Autoimmune pathogenesis for ankylosing spondylitis (AS) and Reiter's genesis for ankylosing spondylitis (AS) and Reiter' syndrome (RS): autoantibodies against an epitope shared by HLA B27 and Klebsiella pneumoniae nitrogenase in sera of HLA B27 patients with
Physicians 1987; 100: 28-39.

29 Ewing C, Ebringer R, Tribbick G, Geysen H M. Antibody activity in ankylosing spondylitis sera to two sites on HLA B27.1 at the MHC groove region (within sequence 65-85), and to a Klebsiella pneumoniae nitrogenase reductase peptide (within sequence 181-199). F Exp Med 1990; 171: $1635-47$.

30 Raybourne R B, Bunning V K, Williams K M. Reaction of anti-HLA-B monoclonal antibodies with envelope proteins of shigella species. Evidence for molecular mimicry in the of shigella species. Evidence for molecular mimicry in the

31 Van Bohemen Ch G, Nabbe A J J B M, Dekker-Saeys A J, et al. Antibodies to enterobacterial cell envelope antigens in al. Antibodies to enterobacterial cell envelope antigens in ankylosing spondylitis. In: Ziff $\mathrm{M}$, Cohen S B, eds. The spondyloarthropathies. Advances in inflammation research. Vol. 9. New York: Raven Press, 1985: 165-71.

32 van Bohemen Ch G, Nabbe A J J M, Landheer J E, et al. HLA-B27M1M2 and high immune responsiveness to Shigella flexneri in post-dysenteric arthritis. Immunol Let 1986; 13: $71-4$. 